\title{
Age-dependent changes in extracellular proteins, aminopeptidase and proteinase activities in Frankia isolate BR
}

\author{
A. MÜLler, ${ }^{1,2}$ P. Benoist, ${ }^{1,2}$ H. G. Diem ${ }^{2}$ and J. SCHWENCKE ${ }^{1 * \dagger}$ \\ 'Laboratoire d'Enzymologie, CNRS, 91198 Gif-sur-Yvette, France \\ 'Laboratoire de Biotechnologie des Symbioses Forestières Tropicales ORSTOM/CTFT-CIRAD, 45 Bis Avenue de la \\ Belle Gabrielle, 94736 Nogent-sur-Marne, France
}

(Received 8 April 1991; revised 12 August 1991; accepted 21 August 1991)

\begin{abstract}
To investigate protein secretion by the nitrogen-fixing actinomycete Frankia isolate BR, we designed a rapid DEAE adsorption, salt elution and Biogel P6DG desalination method to concentrate protein from the growth medium. Secreted proteins reached a maximum concentration $\left(5.6 \mathrm{mg} \mathrm{l}^{-1}\right)$ in the medium at growth arrest. Analysis by SDS-PAGE detected up to 63 extracellular polypeptides when Frankia cells were grown under stirred conditions in BAP medium supplemented with phosphatidylcholine and MES buffer and 65 proteins in stirred BAP media alone. The pattern of extracellular polypeptides changed during growth. Several extracellular proteolytic activities were detected and compared with intracellular ones. The substrate specificity of the extracellular and intracellular aminopeptidase activities were the same. Also, the electrophoretic migration patterns of secreted and intracellular aminopeptidases could not be distinguished. Secretion of the proline-specific aminopeptidase FAP 3.BR appeared to be the only one that arrested at the end of the exponential phase of growth. At least 15 proteinases (PF) were secreted: 10 had the same electrophoretic mobility as their intracellular counterparts after SDS-gelatine-PAGE while five (PF-39.5, PF-38.5, PF-36.5, PF-25.5 and PF-20.5 kDa) had a different electrophoretic mobility and, therefore, appeared to be exclusively extracellular. At least seven extracellular proteinases appeared to increase coordinately in activity shortly before growth arrest.
\end{abstract}

\section{Introduction}

Frankia is a soil-inhabiting actinomycete capable of forming nitrogen-fixing nodules on the root system of a number of non-legumes, now termed actinorhizal plants. Actinorhizal symbiosis was already a subject of interest in the last century (cited in Bond, 1967) but the first confirmed report of the isolation in pure culture of the microsymbiont Frankia was that of Callaham et al. (1978). The ability to cultivate Frankia in vitro has permitted a rapid increase in knowledge of its physiology, mainly of $\mathrm{C}$ - and $\mathrm{N}$-metabolism, nitrogen fixation and related enzymes (Benson \& Schultz, 1990). Very little is known about biochemical changes occurring during

† Present address: Laboratoire de Biotechnologie des Symbioses Forestières Tropicales ORSTOM/CTFT-CIRAD, 45 Bis Avenue de la Belle Gabrielle, 94736 Nogent-sur-Marne, France.

Abbreviations: p-CMS, p-chloromercuriphenylsulphonate; EP, extracellular polypeptides; FAP, Frankia aminopeptidases; MNA, 4-methoxy $\beta$-naphthylamide; PF, Frankia proteinases; TEMED, $N, N, N^{\prime}, N^{\prime}$-tetramethylethylenediamine. hyphal growth and/or production of extracellular proteins, particularly proteases. The main problem in such studies is the heterogenous nature of the mycelial cultures due to unbalanced growth in the static conditions usually employed to cultivate Frankia. In such conditions young and old hyphae as well as sporangia are found together and cells show a varying degree of senescence as indicated by zones of lysis (Benson \& Schultz, 1990). These inconveniences have been overcome for some strains by cultivation in stirred conditions (Murray et al., 1984; Noridge \& Benson, 1986; Diem \& Dommergues, 1990), and also for three of our isolates from Casuarina, by growing them in stirred conditions in well-buffered, BAP mineral medium supplemented with phosphatidylcholine (Schwencke, 1991). Phosphatidylcholines are components of QMOD medium (Lalonde \& Calvert, 1979), but growth of our Frankia strains in this rich medium proved to be quite slow.

Aminopeptidases have been described and proposed to be useful in the characterization of Frankia (Gardes $e t$ al., 1987; Benoist \& Schwencke, 1990), but the significance of Frankia proteases in host-microsymbiont 
interactions has not been explored. Extracellular proteases have been proposed as bacterial pathogenicity factors for Xanthomonas campestris pv. campestris which infects turnip plants (Daniels et al., 1984). Also, several reports indicate that proteinase inhibitors are related to microbial resistance in a number of plants including tobacco, tomato, melon (for reviews see Lamb et al., 1989; Ryan, 1990). These considerations, and others cited above, prompted us to study the secretion of proteolytic enzymes by Frankia in vitro.

\section{Methods}

Origin of Frankia material. Frankia isolate BR (ORS 020608) was isolated by one of us (H.G.D.) in 1983 from young nodules formed on plants of Casuarina equisetifolia after inoculation under axenic conditions with dried nodule samples collected in Brazil. Casuarina nodule lobes were superficially sterilized in a $3 \%(\mathrm{w} / \mathrm{v})$ aqueous solution of osmium tetraoxide for $4 \mathrm{~min}$ to eliminate contaminants harboured in the outer layer of the nodule (Lalonde et al., 1981). Nodule lobes were then thoroughly rinsed in sterile water, chopped into small pieces and transferred into a double layer agar medium as recommended by Diem \& Dommergues (1983). After 10-15 d, Frankia colonies grew out of nodule pieces and exhibited typical hyphae and sporangia. Nitrogenfixing vesicles developed on nitrogen-free medium and, surprisingly, on medium supplemented with Casamino acids (Difco) as nitrogen source. Subsequent infection tests showed that BR was infective and effective on species of genus Casuarina, but not on members of the genus Allocasuarina nor on members of the family Elaeagnaceae.

Growth conditions. Mycelial cells of Frankia isolate BR were disrupted by passing through a syringe and inoculated at $4 \mu \mathrm{g}$ protein $\mathrm{ml}^{-1}$ (Lowry) into $500 \mathrm{ml}$ flasks containing $250 \mathrm{ml}$ of either BAP mineral medium (Fontaine et al., 1986) or BAP medium supplemented with phosphatidylcholine $\left(4 \mathrm{mg}^{-1}\right)$ and $\mathrm{MES} /$ Tris buffer $(10 \mathrm{mM}$, pH 6.8: BAP-PCM) as described by Schwencke (1991). Cells used as inoculum were sporangia-free. Cultures were grown at $28^{\circ} \mathrm{C}$ without shaking or under magnetically stirred conditions.

Preparation of extracellular concentrates. All procedures were carried out at $4{ }^{\circ} \mathrm{C}$ using sterile solutions and laboratory ware. Cultures were harvested by centrifugation at $8000 \mathrm{~g}$ for $15 \mathrm{~min}$. The supernatant was collected and vacuum-filtered through glassfibre filters (Whatman $\mathrm{GF} / \mathrm{F}, 0.7 \mu \mathrm{m}$ passing diameter) and adjusted to $\mathrm{pH} 8.0$ with Tris base. We attempted to concentrate this cell-free medium by using two different methods.

In the first method, the cell-free filtrate was treated twice with $0.4 \mathrm{~g} \mathrm{l}^{-1}$ of pre-swollen DEAE-cellulose (Whatman DE-52) for $30 \mathrm{~min}$ under conditions of slow stirring. The cellulose was collected on Blutex linen cloth (10 $\mu \mathrm{m}$ mesh), resuspended in $20 \mathrm{~mm}$-HEPES/Tris ( $\mathrm{pH} 8.0)$, $10 \%(\mathrm{v} / \mathrm{v})$ glycerol (HTG-buffer), and poured into a $10 \mathrm{ml}$ plastic syringe previously stoppered with glass-wool. The syringe, placed inside a $50 \mathrm{ml}$ plastic tube, was centrifuged in a swinging-bucket rotor at $200 \mathrm{~g}$ for $5 \mathrm{~min}$. Unbound material was removed by washing and centrifuging the packed DEAE-cellulose three times with HTG-buffer. Bound proteins were then eluted by two successive additions of $2 \mathrm{M}-\mathrm{NaCl}$ in HTG-buffer to the packed DEAE-cellulose. After elution for $5 \mathrm{~min}$, the eluate was recovered by centrifugation as above. Rapid desalination was obtained by passing the $2 \mathrm{M}-\mathrm{NaCl}$ eluate over a packed Bio-gel P6DG column built in a plastic syringe by centrifugation (200 $\mathrm{g}$ for $5 \mathrm{~min}$ ). Before packing, the Bio-gel P6DG was equilibrated in $20 \mathrm{mM}-\mathrm{HEPES} / \mathrm{Tris}(\mathrm{pH} 7 \cdot 0), 10 \%(\mathrm{v} / \mathrm{v})$ glycerol,
$25 \mathrm{~mm}-\mathrm{NaCl}$. The volume of $2 \mathrm{~mm}-\mathrm{NaCl}$ used corresponded to $1 / 5$ th of the packed volume of Bio-gel P6DG.

In the second method, the cell-free medium was concentrated through Millipore $10 \mathrm{kDa}$ Ultrafree filtration units to the desired final protein concentration. Extracellular concentrates were used immediately or stored at $-80^{\circ} \mathrm{C}$. Protein concentration was determined by the bicinchoninic acid method according to the manufacturer's (Pierce) instructions using bovine serum albumin as standard.

Electrophoretic conditions. The mixture of secreted proteins was analysed by SDS-PAGE according to the method described by Laemmli $(1970)$ in $14 \%(\mathrm{w} / \mathrm{v})$ acrylamide $/ 0 \cdot 37 \%$ bisacrylamide slab gels containing $0.1 \%$ SDS. The polypeptides were visualized on the gel by the silver stain method (Morrisey, 1981). Proteinase activities were revealed after electrophoresis under denaturing conditions in gelatin/ polyacrylamide gels (Heussen \& Dowdle, 1980) modified as follows. The running gel contained $0.1 \%$ gelatin (freshly prepared), $11 \%$ polyacrylamide, $0.29 \%$ bisacrylamide, $0.375 \mathrm{~mm}-\mathrm{Tris} / \mathrm{HCl}, \mathrm{pH} 8.8$, $0.1 \%$ SDS, $0.05 \%$ ammonium persulphate and $0.025 \%$ TEMED. The stacking gel was $4.5 \%$ acrylamide, $0.23 \%$ bisacrylamide, $0.125 \mathrm{mM}$ Tris $/ \mathrm{HCl}$, pH $6.8,0.1 \%$ gelatin, $0.1 \%$ SDS, $0.05 \%$ ammonium persulphate and $0.1 \%$ TEMED. Following acrylamide polymerization at room temperature, solidification of gelatin was allowed to proceed for $24 \mathrm{~h}$ at $4{ }^{\circ} \mathrm{C}$. Gels were submitted to a pre-electrophoresis at $4^{\circ} \mathrm{C}$ with running buffer (0.05 $\mathrm{M}$-Tris, $0.384 \mathrm{M}$-glycine, $\mathrm{pH} \mathrm{8.3,0.1 \%} \mathrm{SDS,}$ $1 \mathrm{~mm}$-DTT) for $1 \mathrm{~h}$ at $20 \mathrm{~mA}$. The electrophoresis buffer was then changed. Samples were incubated for $15 \mathrm{~min}$ at $37^{\circ} \mathrm{C}$ with denaturing buffer $(2.5 \%(\mathrm{w} / \mathrm{v})$ SDS, $1 \%(\mathrm{w} / \mathrm{v})$ sucrose, $10 \%(\mathrm{v} / \mathrm{v})$ glycerol and $0.5 \%$ bromophenol blue), and loaded immediately. Electrophoresis was done at $12 \mathrm{~mA}$ constant current $\left(4^{\circ} \mathrm{C}\right)$ until the cytochrome $c$ marker reached the bottom of the resolving gel. Then the gels were gently shaken in $2.5 \%(\mathrm{v} / \mathrm{v})$ Triton $\mathrm{X}-100$ in water for $1 \mathrm{~h}$ at room temperature. After six to eight rapid washes with distilled water, the gels were incubated three times for $1 \mathrm{~h}$ at $37^{\circ} \mathrm{C}$ with revealing buffer $(100 \mathrm{~mm}$-glycine $/ \mathrm{NaOH}$, $\mathrm{pH} 8.3,0 \cdot 1 \%$ Triton X-100,1 mM-DTT) and then for $20 \mathrm{~h}$ in fresh revealing buffer. Finally, the gels were washed in distilled water and stained/destained as described by Heussen \& Dowdle (1980). Aminopeptidase activities were revealed after ultralow gelling point agarosePAGE in native conditions as described by Benoist \& Schwencke (1990). In our experiments, $2 \times$ crystallized Serva (10675) acrylamide gave satisfactory results. The following modifications were used for aminopeptidases 1 and 2 from Frankia BR (FAP 1.BR and FAP 2.BR). After washing the gel for $15 \mathrm{~min}$ with $100 \mathrm{mM}-\mathrm{HEPES} / \mathrm{KOH}, \mathrm{pH} 7 \cdot 0$, $100 \mathrm{mM}-\mathrm{NaCl}, 50 \mu \mathrm{M}-\mathrm{CoSO}_{4}$, bands of FAP activities 1 and 2 were revealed with $1 \mathrm{mM}$-L-leucine 4-methoxy- $\beta$-naphthylamide (L-Leu MNA), $\quad 50 \mathrm{~mm}-\mathrm{MES} / \mathrm{TES} / \mathrm{KOH} \quad(\mathrm{pH} 7 \cdot 2), \quad 100 \mathrm{~mm}-\mathrm{NaCl}, \quad 50 \mu \mathrm{M}-$ $\mathrm{CoSO}_{4}$ and $0.025 \%$ Fast Garnet GBC. All other FAP activities were revealed as previously described (Benoist \& Schwencke, 1990). Details of salts used for revealing other FAPs are indicated in Table 1. We stored L-Leu MNA and L-Pro MNA as a $200 \mathrm{mM}$ solution in DMSO at $-20^{\circ} \mathrm{C}$.

Radiolabelling of gelatin. $\left[{ }^{14} \mathrm{C}\right]$ Acetic anhydride [ $\left.540 \mu \mathrm{Ci}(20 \mathrm{MBq})\right]$ was added to $10 \mathrm{ml} 5 \%(\mathrm{w} / \mathrm{v})$ gelatin in sterilized $0.1 \mathrm{~m}$-borate $/ \mathrm{NaOH}$ buffer ( $\mathrm{pH} \mathrm{9.0)} \mathrm{and} \mathrm{the} \mathrm{reaction} \mathrm{was} \mathrm{allowed} \mathrm{to} \mathrm{proceed} \mathrm{for} 2 \mathrm{~h}$ at room temperature. Unincorporated ${ }^{14} \mathrm{C}$ was removed by extensive dialysis at $4{ }^{\circ} \mathrm{C}$ against $10 \mathrm{~mm}-\mathrm{Tris} / \mathrm{HCl}, \mathrm{pH} 7 \cdot 5,100 \mathrm{~mm}-\mathrm{KCl}, 5 \%$ (v/v) glycerol, $2 \mathrm{mM}-\mathrm{NaN}_{3}$. The specific activity of the $\left[{ }^{14} \mathrm{C}\right]$ gelatin was 1500 c.p.m. $(\mu \mathrm{g} \text { protein })^{-1}$. The labelled gelatin was divided into aliquots and stored in liquid nitrogen until use.

Assay of proteolytic activities. Proteolysis of $\left[{ }^{14} \mathrm{C}\right]$ gelatin was measured by adding $10 \mu \mathrm{l}$ of labelled substrate $(46 \mu \mathrm{g}$ protein, $69 \times 10^{3}$ c.p.m.) to $10 \mu \mathrm{g}$ extracellular protein. The volume was adjusted to $0.1 \mathrm{ml}$ with $100 \mathrm{~mm}$-glycine $/ \mathrm{NaOH}, \mathrm{pH} 8.3,0.1 \%$ Triton $\mathrm{X}-100,1 \mathrm{mM}$-DTT buffer and incubated for $16 \mathrm{~h}$ at $37^{\circ} \mathrm{C}$. The reaction 

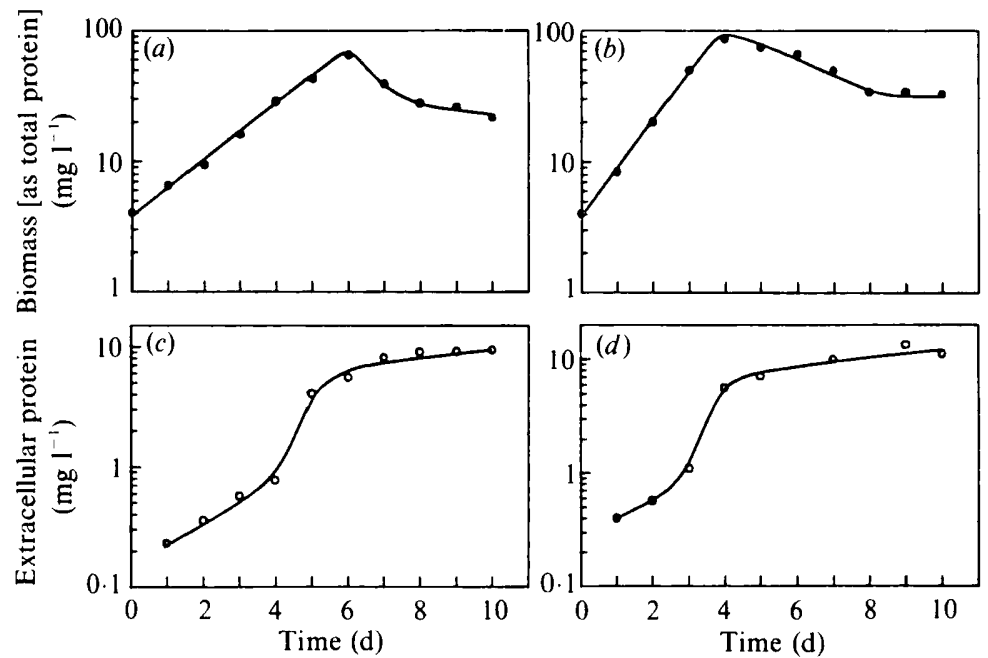

Fig. 1. Kinetics of growth $(\bullet)$ and protein secretion $(O)$ in BAP medium $(a, c)$ and in BAP-PCM medium $(b, d)$. Cells were inoculated at $4 \mathrm{mg} \mathrm{l}^{-1}$ and grown at $28{ }^{\circ} \mathrm{C}$. Duplicate samples were taken at the indicated times and protein concentration was determined using the bicinchoninic acid method for the total cellular fraction $(a, b)$ and extracellular concentrates $(c, d)$.

was stopped by adding $0 \cdot 1 \mathrm{ml} 16 \%(\mathrm{w} / \mathrm{v})$ cold TCA after which the tube was kept on ice for $10 \mathrm{~min}$. The TCA-insoluble material was centrifuged at $9800 \mathrm{~g}$ for $15 \mathrm{~min}$ at $4{ }^{\circ} \mathrm{C}$ and $0.1 \mathrm{ml}$ of the supernatant was mixed with $5 \mathrm{ml}$ of Aquasol and counted.

Assay of aminopeptidase activities in extracellular concentrates. Leucine aminopeptidase activities were assayed by incubating $2.5 \mu \mathrm{g}$ extracellular protein at $37^{\circ} \mathrm{C}$ for $30 \mathrm{~min}$ in $100 \mu \mathrm{l}$ (final volume) of $1 \mathrm{~mm}$-L-Leu-p-nitroanilide, $50 \mu \mathrm{M}-\mathrm{CoSO}_{4}, 100 \mathrm{~mm}-\mathrm{NaCl}, 50 \mathrm{~mm}$ HEPES/Tris ( $\mathrm{pH} 7 \cdot 0$ ). Proline-specific FAP 3.BR was assayed using $10 \mu \mathrm{g}$ of extracellular protein in $100 \mu \mathrm{l}$ (final volume) $1 \mathrm{mM}$-L-Prop-nitroanilide, $200 \mu \mathrm{m}-\mathrm{CoSO}_{4}, \quad 200 \mathrm{~mm}-\mathrm{NaCl}, \quad 50 \mathrm{~mm}-\mathrm{HEPES} / \mathrm{Tris}$ (pH 7.0) for $180 \mathrm{~min}$ at $37^{\circ} \mathrm{C}$. The reaction was stopped with $100 \mu \mathrm{l}$ cold $100 \mathrm{~mm}$-EDTA, $2 \mathrm{~mm}$-o-phenanthroline, $\mathrm{pH} 8 \cdot 0$. The amount of p-nitroanilide released was then measured at $405 \mathrm{~nm}$. One unit of aminopeptidase activity was defined as that which released $1 \mathrm{~mol} p$-nitroanilide $\mathrm{min}^{-1}$. The molar absorption coefficient is $99001 \mathrm{~mol}^{-1} \mathrm{~cm}^{-1}$ at $405 \mathrm{~nm}$ (Masuda et al., 1975)

Inhibition assays of aminopeptidase activities. After electrophoresis and washing with buffer, the gels were cut in slabs and placed into plastic bags. Reversible inhibitors were incubated for $30 \mathrm{~min}$ at room temperature before adding the substrate. Irreversible inhibitors were pre-incubated for $15 \mathrm{~min}$ at $30^{\circ} \mathrm{C}$ with the extracellular protein samples before electrophoresis.

Materials and reagents. Bio-gel P6DG was from Bio-Rad. Ultrafree filter units were obtained from Millipore and Centricon units from Amicon. Bactogelatin (no. 0143-01) was from Difco. Phosphatidylcholine (P4279, type XIII), and Fast Garnet GBC were from Sigma. Ultralow gelling point agarose was from FMC Bioproducts. Antipaïn and leupeptin were from Peptide Institut Inc. (Osaka, Japan). L-Leucine chloromethylketone, $\beta$-naphthylamide, $p$-nitroanilide and 4-methoxy- $\beta$-naphthylamide derivatives of amino acids were from Bachem. Captopril was a gift from Squibb. All other chemicals used were commercial products of analytical grade.

\section{Results}

Kinetics of protein secretion and its relation to microbial growth

Due to the known difficulties with growth of Frankia under static conditions (Benson \& Schultz, 1990), our study was done using Frankia cultures grown under controlled stirred conditions in BAP mineral medium supplemented with phosphatidylcholine and MES buffer (BAP-PCM) as described by Schwenke (1991). A culture under static conditions in BAP medium was also run for comparison.

Results shown in Fig. $1(a, b)$ indicate that under stirred conditions growth of Frankia showed a clearly defined exponential phase. Maximal biomass yield was obtained at day 6 in BAP alone (Fig. $1 a$ ) and at day 4 in BAP-PCM (Fig. 1b); after this the hyphal protein content slowly decreased. Vital staining with acridine orange showed that hyphal lysis started 1 or $2 \mathrm{~d}$ after the end of the exponential growth phase (results not shown). Proteins were secreted throughout the exponential growth phase and showed a significant increase just before growth stopped (Fig. $1 c, d$ ). Virtually no protein was secreted in the stationary phase. The slight increase in extracelluiar protein observed may be due to cell lysis.

Secreted protein amounted to $5.5 \mathrm{mg} \mathrm{l}^{-1}$ at maximal mycelial density (day 6) in BAP medium, and to $5.6 \mathrm{mg} \mathrm{l}^{-1}$ at maximal density (day 4) in BAP-PCM. Similar results were obtained with the two concentration systems employed. We had chosen the DEAE/salt elution desalination system described here because it was far less expensive, more rapid and could easily be adapted for simultaneous processing of multiple samples. Protein secretion by Frankia was quantitatively quite large, amounting to $8.5 \%$ of the total protein in the culture (mycelial + secreted) for BAP-grown cells and $7.0 \%$ for BAP-PCM-grown cells.

\section{Polypeptide patterns of secreted proteins}

A complex pattern of secreted polypeptides was observed after analysis of extracellular concentrates by SDS-PAGE. Under stirred conditions, up to 65 extracelluiar polypeptide (EP) bands were visualized in 


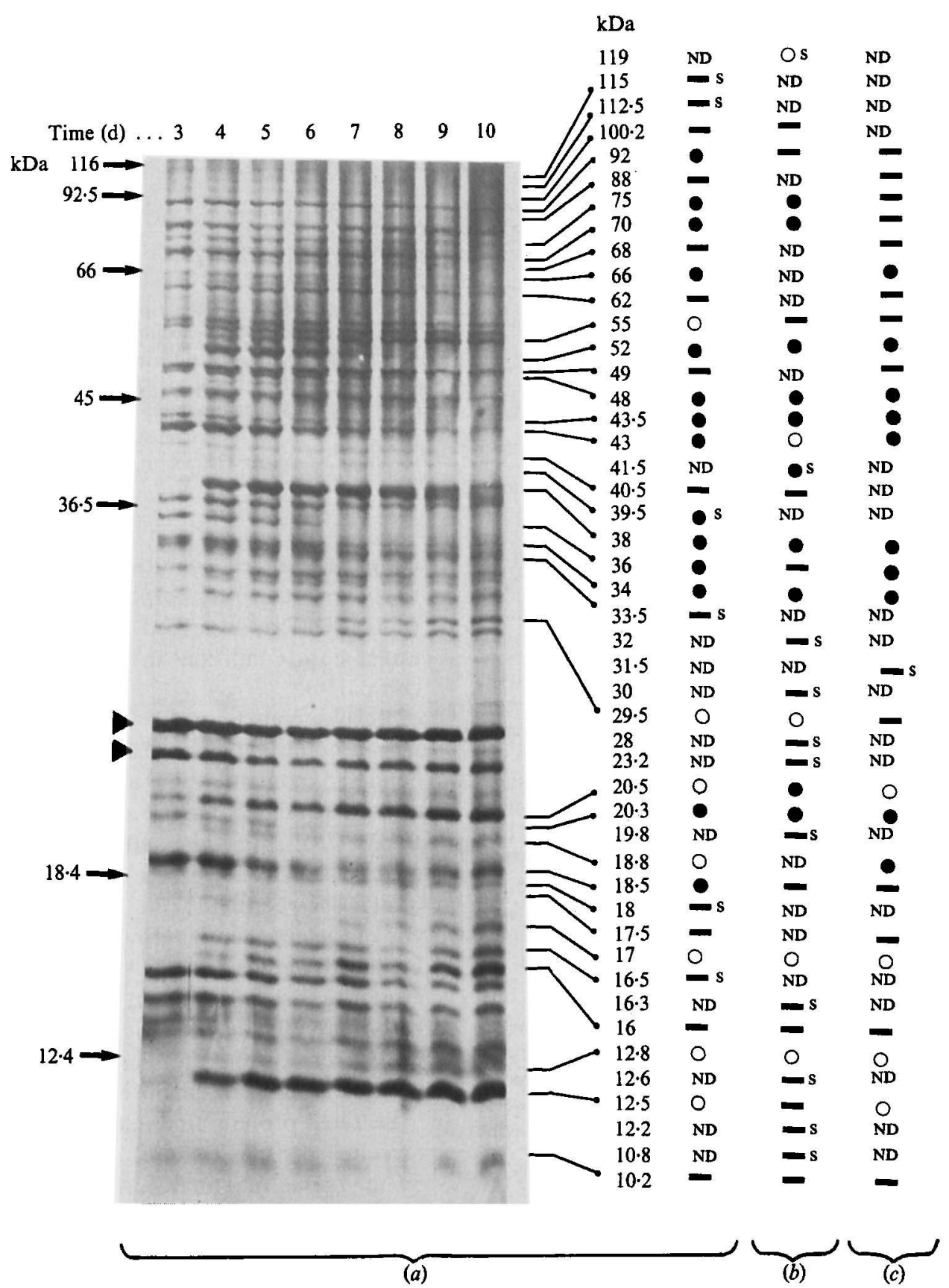

Fig. 2. SDS-PAGE polypeptide pattern of proteins of Frankia sp. BR secreted into stirred BAP medium (a), BAP-PCM medium (b) or unstirred BAP medium $(c)$. Variations in protein bands secreted are represented as follows: $\bullet$, decreasing; $\bigcirc$, increasing; $\square$, no change. Main bands present in all media are indicated with an arrowhead $(\downarrow)$. ND, Polypeptides that could not be detected; $\mathrm{s}$, polypeptides specific to each medium. Molecular mass markers in $\mathrm{kDa}: \beta$-galactosidase, 116 ; phosphorylase $\mathrm{b}$, 92.5 ; bovine serum albumin, 66; chicken egg albumin, 45; L-lactic dehydrogenase, 36.5; $\beta$-lactoglobulin, 18.4; and cytochrome $c$, 12.4.

concentrates from cells grown in BAP medium (Fig. $2 a$ ), while 63 bands were present in concentrates from cells grown in BAP-PCM medium for $4 \mathrm{~d}$ (shown schematically). In static conditions, in BAP medium, 59 extracellular polypeptides bands were found (shown schematically).
Qualitative and quantitative changes in the bands of secreted polypeptides were observed as growth proceeded under the different conditions as shown by the analysis of extracellular concentrates of Frankia cells grown in stirred BAP medium (Fig. $2 a$ ). These changes could be classified as follows. (a) Increase to a certain 


\section{Table 1. Specificity of intracellular and extracellular aminopeptidases of Frankia}

Gel slabs were pre-washed with HEPES buffer as indicated in Methods, and then activities were revealed using a 5 mM concentration of each substrate (naphthylamide or methoxynaphthylamide derivatives). All the substrates were tested for each FAP and only reactive substrates are indicated. Thus, for FAP 3.BR only L-Pro-4-methoxy- $\beta$-naphthylamide was reactive. Relative intensity is indicated by the number of plus signs. Amino-terminal amino acids inside a square box are equally reactive towards intracellular and extracellular FAPs; the others have not been tested for extracellular FAPs.

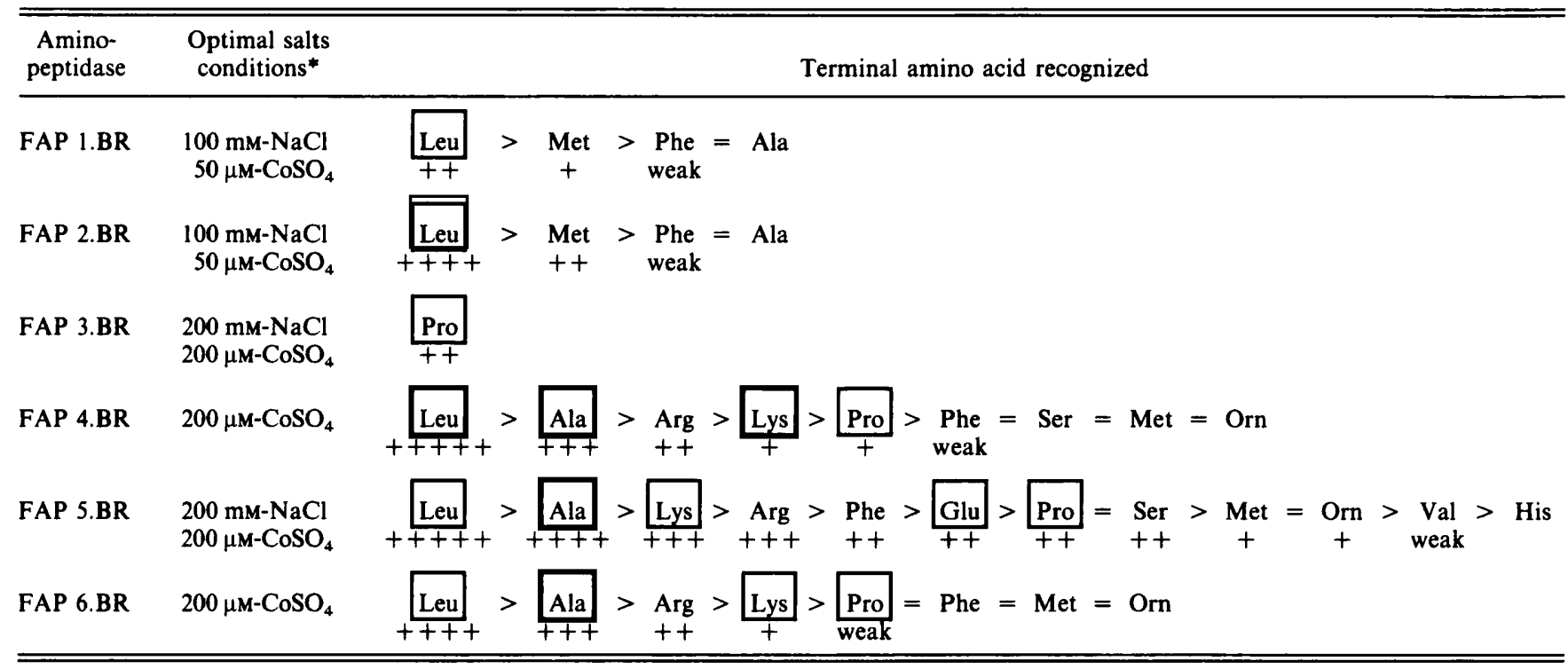

* For revealing the relevant FAP activity.

point in the growth curve and stabilization at this level. Some of these extracellular polypeptides were: a $55 \mathrm{kDa}$ polypeptide (EP-55.0) and also EP-29.5, EP-20.5, EP-18.8 and EP-16.0. (b) Continuous increase starting at some point on the growth curve, i.e. EP-17.0, EP-12.8 and EP-12.5. (c) Increase for a few days then decrease and disappearance, i.e. EP-52 and EP-38. (d) Continuous decrease, i.e. EP-92 (not detectable at day 10), EP-48 and EP-43.5, (not detectable at day 9), EP-36 (not detectable at day 7) and EP-20.3 (not detectable at day 6). Some polypeptides, i.e. EP-75, EP-70 and EP-43 did not disappear during the period of our experiment. (e) Unchanged bands: the majority (33 bands), particularly the two main bands, EP-24.0 and EP-22.0, marked in Fig. 2. Some changes have also been detected among intracellular proteins under each of the different growth conditions (unpublished results). A summary of all the variations in band intensity of extracellular polypeptides is shown in Fig. 2.

Clearly, even when analysing a single strain, extracellular polypeptides showed significant variations depending on growth conditions. Furthermore, some of them (as detailed in Fig. 2), appeared to be specific to a particular growth condition, i.e. EP-115.0, EP-112.5, EP-39.5, EP-33.5, EP-18.0 and EP-16.5 for stirred BAP, while EP-119.0, EP-41.5, EP-32.0, EP-30.0, EP-28.0,
EP-23.2, EP-19.8, EP-16.3, EP-12.6, EP-12.2 and EP-10.8 were specific to stirred BAP-PCM, and EP-31.5 was detected only in BAP medium under static conditions.

\section{Electrophoretic patterns of extracellular aminopeptidases}

After ultralow gelling point native agarose-PAGE (Benoist \& Schwencke, 1990), six extracellular FAPs were detected in concentrates of both BAP and BAPPCM media. No qualitative differences among FAPs were noted for extracellular concentrates obtained from Frankia grown in different media nor in static versus stirred growth conditions. The relative mobility of each of the extracellular FAPs was indistinguishable from that of the corresponding intracellular activity as can be seen in Fig. 3. Furthermore, the specificity of each extracellular FAP was identical with that of its intracellular form (summarized in Table 1).

Secretion of Frankia aminopeptidases with the exception of FAP 3.BR appeared to proceed continuously throughout the period of the experiment. Secretion of FAP 3.BR appeared to be constant up to day 4, then its activity slowly decreased until it was no longer detectable. Intracellular FAP 3.BR activity was detectable up 


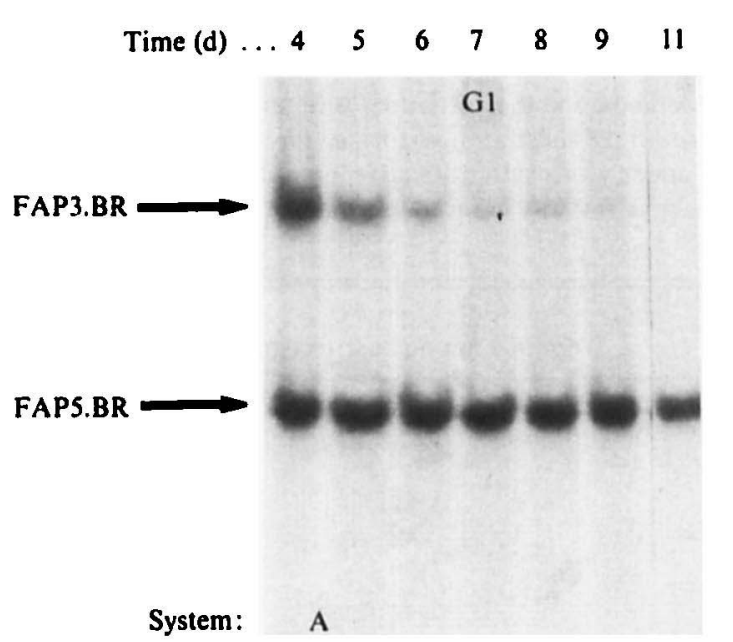

$\begin{array}{lllllll}\text { Days } & 4 & 5 & 6 & 7 & 8 & 9\end{array}$

G3
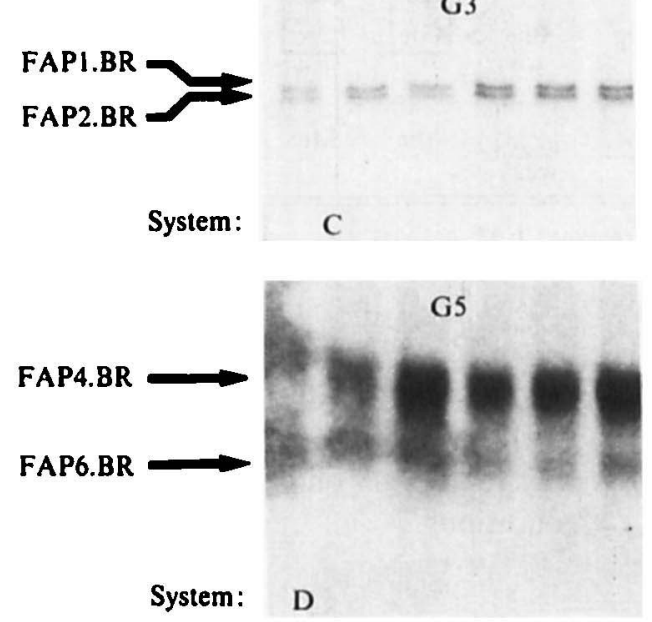
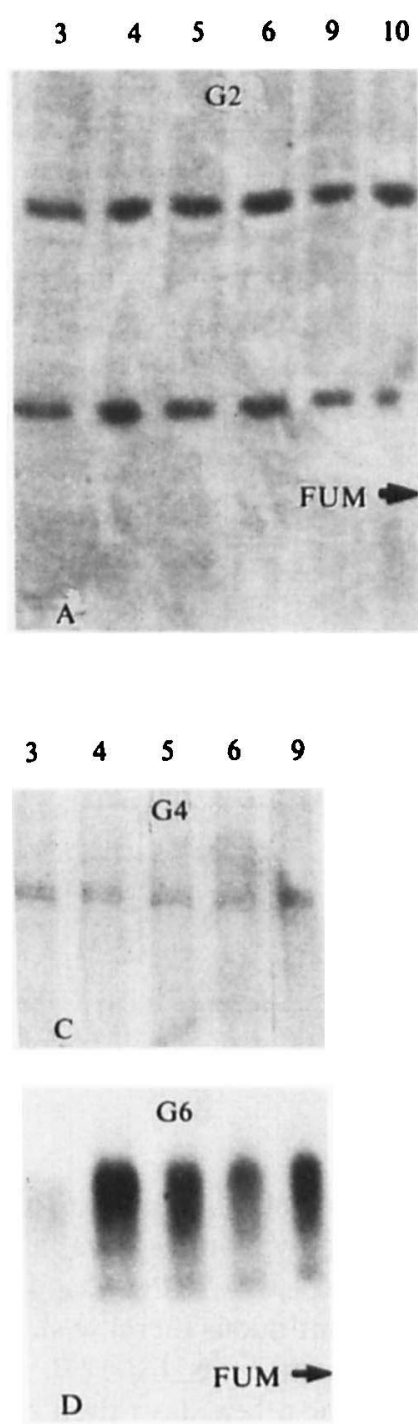

Fig. 3. Electrophoretic pattern of aminopeptidase activities from Frankia cells grown in stirred BAP-PCM medium. G1, G3, G5, extracellular concentrates; G2, G4, G6, intracellular fraction. The position of the prestained fumarase marker (FUM) is indicated.

to day 10 (Fig. 3, gels G1 and G2). Increased secretion of FAP 3.BR starting at day 4 appeared to correspond to a similar increase for the intracellular enzyme (Fig. 3). Secretion of all other extracellular FAPs was unchanged.

\section{Inhibition studies on extracellular aminopeptidases}

Inhibition tests were performed on gel slabs after native agarose-PAGE using L-Leu MNA or L-Pro MNA as substrates. The results (Table 2) show that L-Leucine chloromethylketone and $o$-phenanthroline were general inhibitors of all extracellular FAPs. No inhibitor could be found to differentiate FAP 1.BR from FAP 2.BR, but both were insensitive to $5 \mu \mathrm{M}$-amastatine and $1 \mathrm{mM}$ $p$-chloromercuriphenylsulphonate ( $p$-CMS). Also FAP
4.BR and FAP 6.BR could not be differentiated with the inhibitors tested. FAP 3.BR, specific for amino-terminal proline residues, was the only FAP which was not inhibited by EDTA. Furthermore, $2 \mu \mathrm{g}$ leupeptin $\mathrm{ml}^{-1}$ or 1 mM-PMSF did not inhibit any of the FAPs (not shown). These results indicated that the sum of FAP 1.BR and FAP 2.BR activities could be measured in crude extracts using L-Leu $p$-nitroanilide as substrate in the presence of $0 \cdot 1 \mathrm{mM}-p$-CMS or $5 \mu \mathrm{M}$-amastatin. Also FAP 3.BR could be selectively measured in crude extracts by using L-proline-p-nitroanilide as substrate and $0.5 \mathrm{mM}$-EDTA or $2 \mu \mathrm{M}$-amastatin as inhibitors. The concentration of inhibitors needed for assays in a liquid system was lower than those in the gel-liquid system (Table 2). This was probably due to the diffusion barrier 
Table 2. Minimal concentration of inhibitors for total inhibition (in the gel) of extracellular Frankia aminopeptidases after native agarose-PAGE

Gel slabs were pre-treated with inhibitors for $30 \mathrm{~min}$ before testing for protease activity - see Methods for details. -, without effect; ${ }^{*}$ a very weak band was seen at the concentratons indicated; NT, not tested.

\begin{tabular}{|c|c|c|c|c|}
\hline \multirow[b]{2}{*}{ Inhibitor } & \multicolumn{4}{|c|}{ Minimal inhibitory concentration for: } \\
\hline & FAP $1-2 . B R \dagger$ & FAP 3.BR & FAP 5.BR $†$ & FAP 4-6.BR $\dagger$ \\
\hline EDTA & $5 \mathrm{mM}$ & - & $5 \mathrm{~mm}$ & $5 \mathrm{~mm}$ \\
\hline$o$-Phenanthroline & $3 \mathrm{~mm}$ & $3 \mathrm{~mm}$ & $3 \mathrm{~mm}$ & $3 \mathrm{~mm}$ \\
\hline Bestatine & $5 \mu \mathrm{M}$ & - & - & - \\
\hline Amastatine & - & - & $5 \mu \mathrm{M}$ & $7.5 \mu \mathrm{M}^{*}$ \\
\hline Captopril & NT & $10 \mathrm{~mm}^{*}$ & $10 \mathrm{~mm}$ & NT \\
\hline Leu-chloromethylketone & $5 \mathrm{mM}$ & $5 \mathrm{~mm}^{*}$ & $1 \mathrm{~mm}$ & $1 \mathrm{~mm}$ \\
\hline p-Chloromercuriphenylsulphonate & - & $0.5 \mathrm{~mm}^{*}$ & $0.5 \mathrm{~mm}$ & $1 \mathrm{~mm}^{*}$ \\
\hline
\end{tabular}

$\dagger$ Using $1 \mathrm{~mm}$-L-Leu-4-methoxy- $\beta$-naphthylamide as substrate.

$\ddagger$ Using 1 mM-L-Pro-4-methoxy- $\beta$-naphthylamide as substrate.

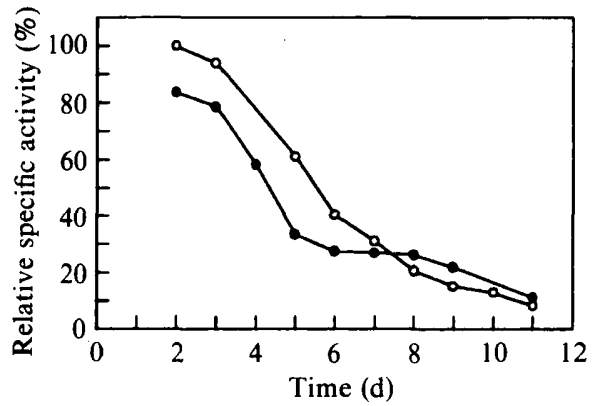

Fig. 4. Variation of extracellular FAP 3.BR activity as a function of the age of the culture in BAP medium (๑) and BAP-PCM medium $(O)$. L-Pro-p-nitroanilide was used as substrate and $0.5 \mathrm{~mm}$-EDTA was added as a specific inhibitor for all the other aminopeptidase activities (see Table 2). $100 \%$ FAP3.BR specific activity corresponds to $5.3 \times$ $10^{-6}$ units $\mathrm{mg}^{-1}$.

present in the gel-liquid system. Finally, the selective determination of FAP 5.BR could be achieved by using glutamic acid $p$-nitroanilide as substrate. From the data obtained, no conditions could be found for the selective determination of FAP 4.BR and/or FAP 6.BR in crude extracellular concentrates.

Based on these results we were able to specifically measure the variations in FAP 3.BR activity in crude extracts. As shown in Fig. 4 a similar rapid decrease in extracellular FAP 3.BR specific activity after day 3 was observed in both BAP medium and BAP-PCM medium.

Taken together, our findings suggest that all Frankia aminopeptidases (except perhaps FAP 3.BR) are metalloenzymes. Furthermore, they can be classified into two groups according to their sensitivity to inhibitors. The first group, including FAP 1-2.BR, is sensitive to bestatine which inhibits aminopeptidase B (EC 3.4.11.6) and leucine aminopeptidase (EC

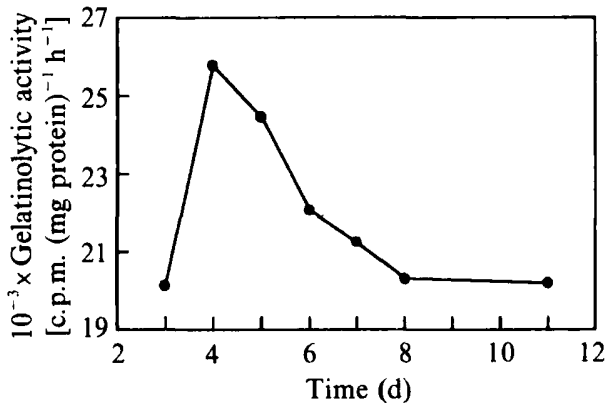

Fig. 5. Extracellular gelatinolytic activity in stirred BAP-PCM medium.

3.4.11.1) (Umezawa et al., 1976). The second group, comprising FAPs 4-5-6.BR, is sensitive to amastatin which inhibits aminopeptidase A (EC 3.4.11.7) and leucine aminopeptidase (Aoyagi et al., 1978).

Variation of whole extracellular gelatinolytic activity as a function of the age of the culture

Overall extracellular proteolytic activity could be measured using $\left[{ }^{14} \mathrm{C}\right]$ gelatin as substrate in the presence of $0.1 \%$ Triton $\mathrm{X}-100 .\left[{ }^{14} \mathrm{C}\right]$ Casein was only marginally degraded under similar conditions. As shown in Fig. 5, global extracellular gelatinolytic activity showed a peak at day 4 in BAP-PCM medium in stirred conditions. This corresponded to both maximal growth in BAP-PCM medium and arrest of secretory activity (Fig. $1 b, d$ ). These results are in good agreement with the variations in band activities obtained by electrophoretic analysis of the extracellular proteolytic activities discussed below. Cells grown in BAP medium, but in static conditions also 


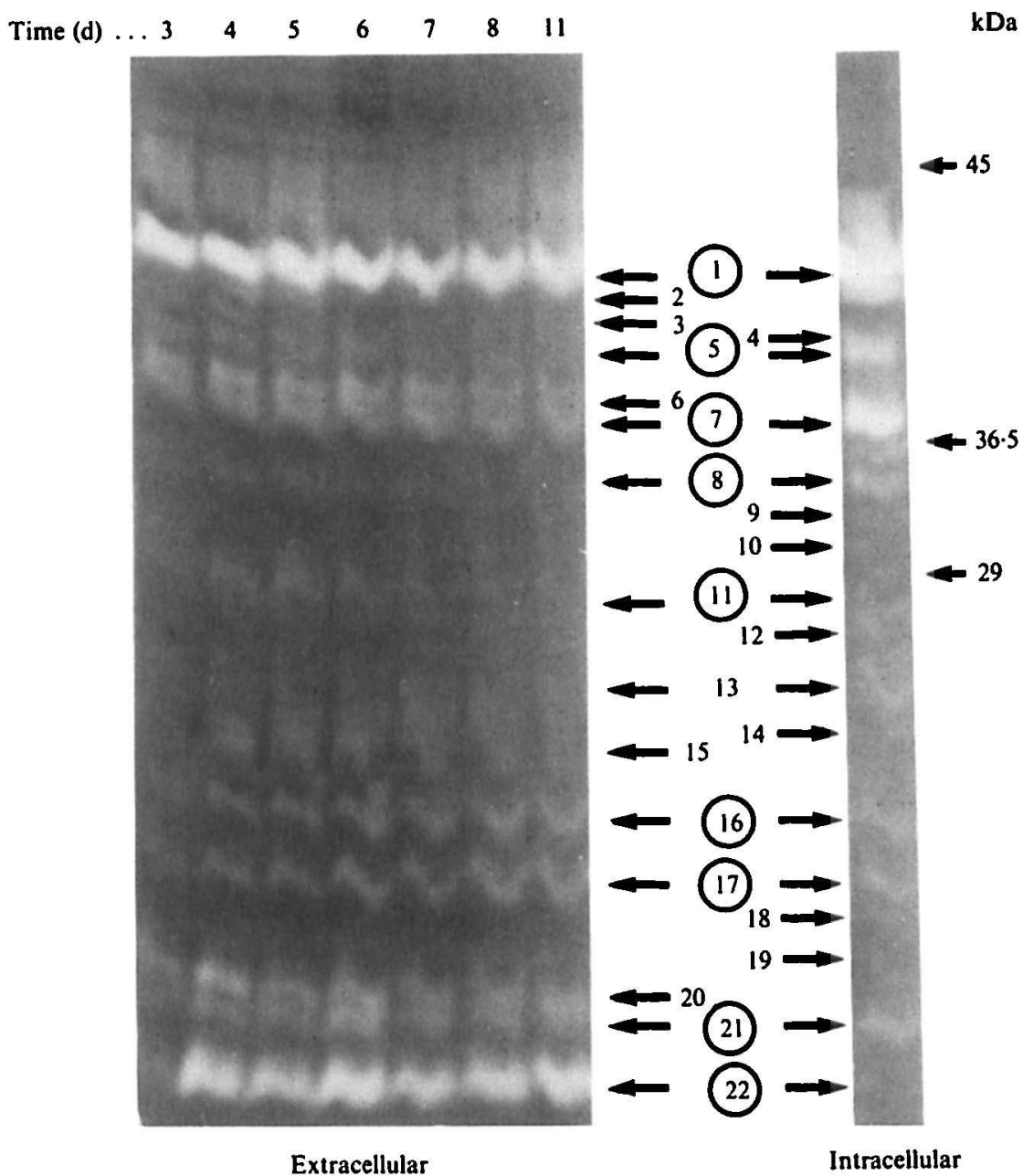

Fig. 6. SDS-gelatin-PAGE analysis of Frankia proteinases. Bands of extracellular activities are arrowed to the left. For comparison, bands of intracellular activities are arrowed to the right. Encircled numbers indicate bands of proteolytic activities present both extracellularly and intracellularly. secreted proteolytic activiteis. Maximal secretion and gelatinolytic activity were also coincidental with growth arrest (results not shown).

\section{Electrophoretic analysis of extracellular proteolytic activities}

Up to 15 proteinases were secreted when Frankia BR cells were grown in BAP-PCM medium under stirred conditions (Fig. 6). Proteinases were visualized after treatment of extracellular extracts $(100 \mu \mathrm{g}$ protein) with $2.5 \%$ SDS, $1 \%$ sucrose, $0.5 \%$ bromophenol blue at $37^{\circ} \mathrm{C}$ for $15 \mathrm{~min}$ and analysis by SDS-gelatine-PAGE. The presence of $1 \mathrm{~mm}$-DTT was essential for good results. In Fig. 6, Frankia intracellular and extracellular proteinases (PF) were compared for electrophoretic mobility and classified from the lowest migration rate (PF-1) to the highest (PF-22). Only five of the secreted proteinases were exclusively extracellular, while seven were exclusively intracellular, and 10 secreted activities were found
Table 3. Localization, molecular mass and nomenclature of Frankia proteinases

These data were obtained from Fig. 6 .

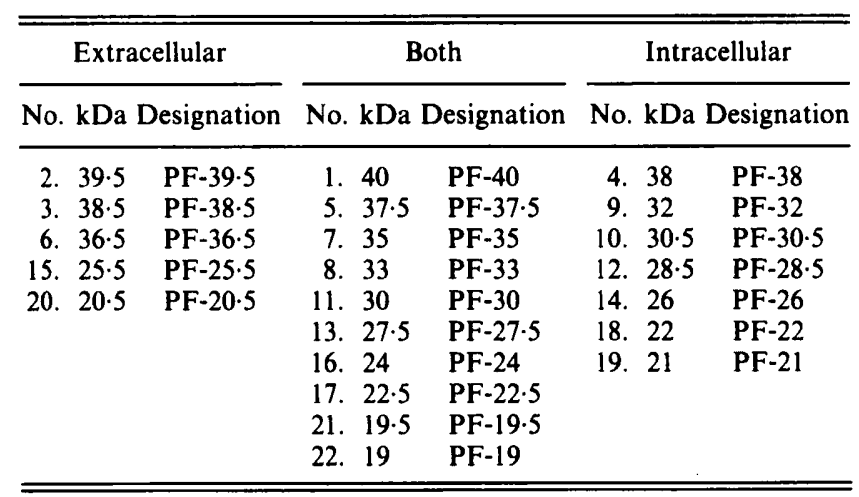

to be both. The molecular mass of each proteinase and their localization are indicated in Table 3.

Analysis of the electrophoretic pattern of extracellular 
proteinases as a function of age in BAP-PCM medium indicated that for some of them (i.e. PF-8, $-11,-15,-16$, $-17,-20,-21$ and -22$)$ there was a sharp and coordinate increase at day 4 that coincided with growth arrest under these conditions (Fig. 1a). Slight decreases of activity were also observed after day 5 for PF-3, $-5,-8,-11$ and -20. This may explain the variations observed when measuring global gelatinolytic activities as a function of the age of the culture under the same conditions (Fig. 5).

\section{Discussion}

In this paper we describe changes in extracellular proteins, particularly proteinases and aminopeptidases, of Frankia BR as a function of age and different growth conditions. Frankia BR cells secreted a variety of proteins during exponential growth under stirred conditions. Protein secretion also occurred during unbalanced growth under batch conditions, indicating that it is an intrinsic property of Frankia cells and is independent of culture conditions.

Cells grown under stirred conditions in BAP-PCM medium secreted proteins at a higher rate than in stirred BAP medium alone, indicating that both phosphatidylcholine and MES buffer present in BAP medium may play a role in the secretion process. Phosphatidylcholines are ubiquitous membrane constituents and may influence membrane fluidity and integrity. On the other hand, cells grown under stirred conditions, in the presence of phosphatidylcholine and MES buffer, show a characteristic 'open mesh' type mycelium (Schwencke, 1991), and this may enhance the elimination of waste products as well as secretion. Furthermore, several authors (Chahal \& Nada, 1976; Fairbain \& Law, 1987; Strasser de Saad et al., 1987) have found that a $\mathrm{pH}$ around $6 \cdot 8-7 \cdot 0$ is optimal for secretion of some proteins. This condition was obtained by addition of MES buffer to the Frankia culture which otherwise became alkaline during growth.

Secretion of proteins increased just before growth arrest in exponentially growing cells and ceased at growth arrest. The slight increase observed thereafter is most probably due to the release of intracellular protein after cell lysis. Similar behaviour was observed for cells growing in unbalanced static conditions. We also found a number of qualitative and quantitative changes in the pattern of secreted proteins depending on the age of the culture as well as on the nature of the medium. This suggests that Frankia has a considerable ability to adapt to varying physiological conditions. The SDS-PAGE patterns of these proteins, which have been proposed as a valuable approach to the identification of Frankia strains and other actinomycetes species (Benson \& Hanna, 1983; Gardes \& Lalonde, 1987; Dietz, 1988), should therefore be interpreted with caution. In contrast, intracellular aminopeptidase patterns were found to be remarkably stable in cultures of different ages, confirming the suggestion that they may be useful for strain classification (Gardes et al., 1987; Benoist \& Schwencke, 1990). Furthermore, extracellular aminopeptidases did not show any age-dependent changes, with the exception of FAP 3.BR, specific for proline, which showed a significant decrease after cell growth arrest, although the intracellular enzyme activity remained unchanged. Whether loss of extracellular activity is due to arrest of secretion or proteolytic degradation or both remains an open question.

Extracellular and intracellular aminopeptidases shared the same substrate specificity and electrophoretic migration values. However, they are not necessarily identical as minor changes in molecular mass and biochemical properties may be undetectable by the methods employed here. The same can be said for intracellular and extracellular proteinases having similar electrophoretic migration characteristics.

Although gelatinolytic activity was previously reported in some strains of Frankia (Horrière, 1984), this paper is the first report of secretion of proteinases by Frankia. The ability of Frankia to secrete proteinases is not surprising, as proteinase secretion is well-documented for the genus actinomycete Streptomyces [Renko et al., 1981; Peczynska-Czok \& Mordarsky, 1988 (review); Aretz et al., 1989]. The fact that several extracellular proteinases showed a coordinate rise in activity at growth arrest is intriguing. One possible explanation is increased secretion of high-molecular-mass proteinase complexes (proteasomes). Current work (unpublished) from our laboratory supports this hypothesis. It is also interesting to note that periplasmic proteasomes have been proposed to exist in $E$. coli (Vaithilingam \& Cook, 1989).

Because studies of Frankia proteinases are very scanty, their physiological role is not clearly understood. Proteinases have been proposed to play a role in a diversity of processes (Bond \& Butler, 1987). Further work will be required to define their function(s) in Frankia.

We thank Dr S. Brown from the ISV for facilitating access to their microscopy section and Dr P. England for reading and correcting the English text. This work has been funded in part by the Ministère de la Recherche (contract MRT 88T0807).

\section{References}

Aoyagi, T., Tobe, H., Kojima, F., Hamada, M., Takeuchi, T. \& UMEZAWA, H. (1978). Amastatin, an inhibitor of aminopeptidase A, produced by actinomycetes. Journal of Antibiotics 6, 636-638. 
Aretz, W., Koller, K. P. \& Riess, G. (1989). Proteolytic enzymes from recombinant Streptomyces lividans TK 24. FEMS Microbiology Letters 65, 31-36.

BENOIST, P. \& SCHWENCKE, J. (1990). Native agarose polyacrylamide gel electrophoresis allowing the detection of aminopeptidase, dehydrogenase and esterase activities at the nanogram level: enzymatic patterns in some Frankia strains. Analytical Biochemistry 187, 337-344.

Benson, D. R. \& HanNa, D. (1983). Frankia diversity in an alder stand as estimated by sodium dodecyl sulfate-polyacrylamide gel electrophoresis of whole-cell proteins. Canadian Journal of Botany 61, 2919-2923.

Benson, D. R. \& Schultz, N. A. (1990). Physiology and biochemistry of Frankia in culture. In The Biology of Frankia and Actinorhizal Plants, pp. 107-127. Edited by C. R. Schwintzer \& J. D. Tjepkema. San Diego: Academic Press.

BoND, G. (1967). Fixation of nitrogen by higher plants other than legumes. Annual Review of Plant Physiology 18, 107-126.

BOND, J. S. \& BUTLER, P. E. (1987). Intracellular proteases. Annual Review of Biochemistry 56, 333-364.

Callaham, D., Del. Tredici, P. \& Torrey, J. G. (1978). Isolation and cultivation in vitro of the actinomycete causing root nodulation in Comptonia peregrina. Science 199, 899-902.

Chahal, D. S. \& Nanda, S. K. (1976). A screening of some actinomycetes for protease production. Proceedings of the Indian National Science Academy 41, 427-434.

Daniels, M. J., Barber, C. E., Turner, P. C., Sawczyc, M. K., BYRDE, R. J. W. \& Fielding, A. H. (1984). Cloning of genes involved in pathogenicity of Xanthomonas campestris pv. campestris using the broad host range cosmid pLAFRl. Embo Journal 3, 3323-3328.

Diem, H. G. \& Dommergues, Y. (1983). The isolation of Frankia from nodules of Casuarina. Canadian Journal of Botany 61, 2822-2825.

DiEM, H. G. \& Dommergues, Y. (1990). Current and potential uses and management of Casuarinaceae in the tropics and subtropics. In The Biology of Frankia and Actinorhizal Plants, pp. 317-342. Edited by C. R. Schwintzer \& J. D. Tjepkema. San Diego: Academic Press.

DieTz, A. (1988). Practical and proposed cooperative investigational criteria for taxonomic studies of the Actinomycetes. In Biology of Actinomycetes '88, pp. 203-209. Edited by Y. Okami, T. Beppu \& H. Ogawara. Tokyo: Japan Scientic Societies Press.

Fairbairn, D. J. \& Law, B. A. (1987). The effect of nitrogen and carbon sources on proteinase production by Pseudomonas fluorescens. Journal of Applied Bacteriology 62, 105-113.

Fontaine, M. S., Young, P. H. \& Torrey, J. S. (1986). Effects of long-term preservation of Frankia strains on infectivity, effectivity and in vitro nitrogenase activity. Environmental Microbiology 51, 694-698.

GARDES, M., Bousquet, J. \& LALONDE, M. (1987). Isozyme variation among 40 Frankia strains. Applied and Environmental Microbiology 53, 1596-1603.

GARDES, M. \& LALONDE, M. (1987). Identification and subgrouping of Frankia strains using sodium dodecyl sulfate-polyacrylamide gel electrophoresis. Physiologia Plantarum 70, 237-244.

Heussen, C. \& Dowdle, E. B. (1980). Electrophoretic analysis of plasminogen activators in polyacrylamide gels containing sodium dodecyl sulphate and copolymerized substrates. Analytical Biochemistry 102, 196-202.

HORRIÈRE, F. (1984). In vitro physiological approach to classification of Frankia isolates of the Alnus group based on urease, protease and $\beta$-glucosidase activities. Plant and Soil 78, 7-13.

LAEMMLI, U. K. (1970). Cleavage of structural proteins during assembly of the head of bacteriophage T4. Nature, London 227, 680-685.

Lalonde, M. \& Calvet, H. E. (1979). Production of Frankia hyphae and spores as an infective inoculant for Alnus species. In Symbiotic Nitrogen Fixation in the Management of Temperate Forests, pp. 95-110. Edited by G. C. Gordon, C. T. Wheeler \& D. A. Perry. Corvallis: Oregon State University.

Lalonde, M., Calvert, H. E. \& Pine, S. (1981). Isolation and use of Frankia strains in actinorhizal formation. In Current Perspectives in Nitrogen Fixation, pp. 296-299. Edited by A. H. Gibson \& W. E. Newton. Canberra: Australian Academy of Science.

Lamb, C. J., Lawton, M. A., Dron, M. \& Dixon, R. A. (1989). Signals and transduction mechanisms for activation of plant defenses against microbial attack. Cell 56, 215-224.

Masuda, T., Mayashi, R. \& Hata, T. (1975). Aminopeptidases in the acidic fraction of the yeast autolysate. Agricultural and Biological Chemistry 39, 499-505.

MORRISEY, J. M. (1981). Silver stain for proteins in polyacrylamide gels: a modified procedure with enhanced uniform sensitivity. Analytical Biochemistry 117, 307-310.

Murray, M. A., Fontaine, M. S. \& Torrey, J. G. (1984). Growth kinetics and nitrogenase induction in Frankia sp HFP-ArI 3 grown in batch culture. Plant and Soil 78, 61-78.

NORIDGE, N. A. \& BENSON, D. R. (1986). Isolation and nitrogen-fixing activity of Frankia sp. strain CpIl vesicles. Journal of Bacteriology 166, 301-305.

PeCzynsKa-CZOCH, W. \& Mordarski, M. (1988). Actinomycete enzymes. In Actinomycetes in Biotechnology, pp. 219-283. Edited by M. Goodfellow, S. T. Williams \& M. Mordarski. London: Academic Press.

Renko, M., Pokorny, M., Vitale, L. J. \& TURK, V. (198I). Streptomyces rimosus extracellular proteases. 2. Isolation and characterization of serine alkaline proteinase. European Journal of Applied Microbiology and Biotechnology 11, 166-171.

RYAN, C. A. (1990). Protease inhibitors in plants: genes for improving defenses against insect and pathogens. Anmual Review of Phytopathology 28, 425-449.

SCHWENCKE, J. (1991). Rapid growth and increased biomass yield for some Frankia strains in buffered stirred mineral medium (BAP) added of phosphatidyl cholines. Plant and Soil 137, 37-41.

Strasser de SaAd, A. M., Manca de Nadra, M. C., Pesce, A. A., De RUIZ HOLGADO \& OlIVER, G. (1987). Effect of cultivation conditions on proteinase production by Lactobacillus murinus. Folia Microbiologica 32, 85-88.

Umezawa, H., Aoyagi, T., Suda, M., Hamada, M. \& Takeuchi, T. (1976). Bestatin, an inhibitor of aminopeptidase B, produced by actinomycetes. Journal of Antibiotics 1, 97-99.

VAITHILINGAM, I. \& COOK, R. A. (1989). High-molecular-mass proteases (possible proteasome) in Escherichia coli $\mathrm{K}-12$. Biochemistry International 6, 1297-1307. 